\title{
Study on the Holism Thoughts in Contemporary Chinese Primary and Secondary Schools Education
}

\author{
Mengmeng Tian \\ 1343860595@qq.com
}

Keywords: Sinology; Holism; Filial piety

\begin{abstract}
Sinology and traditional culture are increasingly valued in primary and secondary education nowadays. Not only ancient poetry and classical Chinese learning, but even Go, Chinese painting, and traditional etiquette rise together. In the study of traditional culture, it is indispensable to learn ancestors' deeds and read ancient classics, and holistic thoughts can be seen everywhere in the deeds of classics and books. The holistic thought is opposite to the individualistic thought, emphasizing the country standard and the family standard, and is the main value principle and value orientation of ancient Chinese society. The holistic thought emphasizes that individual interests are subject to the overall interests, and individuals must live for the family and the nation. In the classical literature, this kind of thought can be seen everywhere. The holistic thought in the contemporary Chinese primary and secondary school education is mainly reflected in the view of filial piety.
\end{abstract}

\section{Introduction}

In recent years, Chinese traditional culture and sinology have received increasing attention from people. Popular "sinology fever" has gradually spread to primary and secondary schools. In particular, the reform of primary and secondary school teaching materials in 2017 added the section of ancient poetry reading, which further encouraged the culture of "sinology fever", which means ancient poetry reading will be added in the examination from primary to junior middle school and from the junior middle school to the senior middle school. Related to the examination, parents will pay special attention to it. And Chinese learning training institutions in various cities and towns have sprung up. The traditional enlightened reading materials, such as Disciple Gauge, Analects of Confucius, and Three Character Classics, One Hundred Family Names and One Thousand Essays, are put on the stage of modern education. The holistic thoughts can be seen everywhere in these classic documents.

\section{The Connotation of Holism}

The holism thought is opposed to individualism and emphasizes the overall interests. The performance in the traditional Chinese society is the value orientation of the country standard and the family standard, such as the selflessness spirit of King Yu who didn't go back when passing his home to tame the flood; Shang Yang erected a wood pile to win the trust of people; $\mathrm{Zi} \mathrm{Lu}$ carried rice walking for one hundred miles to cook meal for his parents; rise and fall of a nation rests with every one of its citizens. Holism is the main value orientation and value principle of Chinese ancient society. Mr. Feng Qi believes that the Chinese traditional philosophy mainly proposes the principles of the value system from three aspects: "the debate over nature and man", "the debate over group and self", and "the debate over reason and desire". Among them, "the debate over group and self" is about the whole and the individual, and the idea of "group" belongs to the category of holism. For example, in ancient Chinese society, the term "holism" did not appear clearly. However, the whole concept of value in ancient societies deeply contains the idea of holism. Scholar Liu Xiaohong points out in his article On the Holism in the Chinese Traditional Value System and its Changes in Modern Times that holism is a basic tendency of traditional Chinese culture and an important principle of the traditional value system, clarifying the direction of the development of ancient holism. Scholar Chen Jianping points out that "holism is an extremely important moral 
principle that permeates the ancient Chinese society, especially the feudal society." in his article $O n$ Chinese Traditional Holism. In the article, the spirit of patriotism is particularly emphasized. Scholar Li Ruilan and Ji Naili discuss the necessary possibilities for applying and enhancing holistic values in the process of world modernization in their book New Theory of Self Cultivation, Family Harmony, Country Management and World Peace - Rational and Modern Values of Chinese Traditional Holistic Values. From the Spring and Autumn period to the Qin and Han Dynasties, from the Sui and Tang Dynasties to the Song, Yuan, Ming, and Qing Dynasties, the development and inheriting of the mainstream values and these mainstream values are accompanied by a clear holistic tendency, and also demonstrate the rationality and significance of holistic values in contemporary social development. From the arguments of the above scholars, we can see that holism not only exists in ancient Chinese society but also plays a very important role. It is reflected in traditional classics, and it is also true in Chinese education.

What's analyzed in this paper is the manifestation of holism in contemporary Chinese primary and secondary school education. The most important content is the concept of filial piety. The most prominent manifestation of the state-based idea in the holism thought in ancient times is the national-centered ideology of loyalty, patriotism, and patriotism. The most direct embodiment of contemporary thought is the "Chinese dream." The concept of family standard emphasizes the responsibility of the individual to the family, that is, the responsibility of individual in the complex ethical relationship is filial piety. The Chinese nation has always attached great importance to family ethical relations. Analects of Confucius - While Learning describes that there are seldom people who show filial obedience to their parents, obey their elder brothers but violate the upper rulers. There are no people who don't like violating the upper rulers but like rebelling. If gentlemen focus on the fundamental things and complete them, the principles for administering a county and behaving for individuals are established. It's the basis to show filial obedience to parents and obey elder brothers. Confucians believe that the meaning of filial piety is to become a benevolent person's fundamental, and filial piety is not only the root for a gentleman but also the root to become a benevolent person. People who understand filial piety can fulfill their obligation to support their parents. Moreover, such people are comfortable with their own affairs and obey the social order. They will not commit crimes. This is the meaning of using filial piety to teach people. Filial piety is not only the basic bond to maintain family affection, but also an important factor affecting social stability. Filial piety is the important idea of the family standard, and it is also an outstanding performance of holism. In today's "sinology fever", the main manifestation of the holistic thought in contemporary Chinese primary and secondary school education is filial piety.

\section{The Reflection of the Meaning of Filial Piety in Primary and Secondary Education}

The concept of China's filial piety has a history of several thousand years. The word "filial piety" has appeared in the inscriptions on bones or tortoise shells of the Shang Dynasty and the Chinese nation has traditionally admired the traditional virtues of "filial piety". Filial piety is also an important point of Confucianism. The interpretation of filial piety by Erya Shixun is "good at serving parents is filial piety." The interpretation of Shuowen Jiezi is "the people who can treat their parents well from old generation to current generation, inherit filial piety from generation to generation." In the inscriptions on ancient bronze objects, filial piety is interlinked with Lao and Kao. While in the meaning of "teaching", the first and most fundamental is to cultivate people's filial piety, filial virtues, and filial piety through education, so The Classic of Filial Piety made a further explanation of filial piety. "Filial piety is the fundamental of moral conduct and all the civilization is produced on the basis of filial piety". It teaches people the rite and to understand the filial piety. Book of Rites makes another further explanation for filial piety that such filial people can inherit the unfulfilled wish of their ancestors and develop their unfulfilled undertaking, which means continuing the unfulfilled undertaking, and inherit the unfulfilled wish on the basis of serving and respecting parents, which enriches the connotation of filial piety and improves it. Filial piety is the basic of social ethics. From Confucianism's point of view, filial piety is divided into two aspects: live and dead. During the parents' lifetime, children perform filial piety towards their 
parents and make every effort to serve them. When they die, their children still have to have parents in mind to mourn, keep vigil beside their coffin and inherit family business. At this point, it can be called "the end of serving parents." The filial piety in today's primary and secondary school education mainly focuses on serving in parents' lifetime.

Since the "cultural fever" in the 1980s, many people have dedicated themselves to the propagation and inheritance of traditional Chinese culture by revitalizing traditional culture as missions. The exam-oriented education that has been intensifying has led to the neglect of the cultivation of students' humanistic spirit and moral qualities since the 1990s, prompting many people to turn their attention to traditional culture, hoping to solve the negative effects of utilitarian education through traditional culture. As an important carrier of traditional culture, sinology has received increasing attention from people. Under the impetus of these two forces, the first extensive marriage between sinology and modern education emerged after the founding of New China: colleges and universities set up sinology education majors and cultivated specialized talents; "Chinese classic reading activities" flourished throughout the country; the school-based curriculum of sinology in the primary and secondary schools, various forms of sinology training classes, and the sinology schools have been launched one after another, forming an upsurge of sinology. Confucius is honored as a saint. Many schools have imitated the ancient opening ceremony this year. The school holds a grand pen ceremony, wearing costumes, performing enlightenment and tracing, learning to write the word "person", and saying thanks to parents. Thanksgiving education is popular in teaching activities. The filial respect of parents is the main activity that is often set up, such as helping parents to do housework, pounding elders' back. Of course, these activities are all positive. The combination of knowledge and practice allows children to grow in a good environment.

In addition to the school's filial piety education for Chinese culture, there are also many sinology training institutions outside the school that grow wildly and being pursued after by students and parents. Taking the sinology leaning halls in Hangzhou as an example, the author mainly investigated three sinology halls: East Study Room, Jing Zhou Academy, and Xiao Fuzi Sinology Hall. Their teaching contents mainly include Disciple Gauge, Three Character Classics and The Analects of Confucius, and One Thousand Character Primer. They usually organize many traditional folk activities. The most important one is the promotion of filial piety, taking Confucius as a saint. The decorations of various academies are of antique beauty. There are many stories admiring filial piety on the walls, such as Cai Shun mining mulberry, lying ice seeking carp, Kong Rong giving up the biggest pear. Disciple Gauge regulates and summarizes a person's words, deeds and behaviors from day to day, from filial piety and fraternal duty to standing, sitting and sleeping, so it is used to teach kindergartens in various sinology halls to advocate the meaning of filial piety. It edifies the children's morally nurture from personality level. For example, Disciple Gauge: Parents call, should not slow. Parents' order, do not be lazy. Parents 'edification, we must listen. Parents' blame must be upheld" is to teach children to obey their parents. Analects of Confucius • Weizheng contains: "today, many people think that filial piety is just to support their parents. But as for dogs and horses, they are also supported by people. If one cannot respect parents, it's not filial piety." If you only meet the physical needs of parents, but cannot respect parents, is this different with keeping the dog and horse? It is to say that when children communicate with their parents, they must maintain a pleasing attitude. They cannot be spoiled. Another example is the Three Character Classics: "As for a Son, when you are a little boy, you must be close to your teachers and friends. When Huang Xiang was nine years old, and he can warm his father's bed. This behavior is not only what you should do but what you should learn and follow up. When Kong Rong was four years old, he can give up the biggest pear. We all should know such moral conduct of respecting elder brothers." The story of Huang Xiang warming bed and Kong Rong giving up the biggest pear tell children to learn etiquette from childhood and to learn humility and filial piety from these two children.

There are many similar stories like this. The sinology schools will pick an ancient classic story to tell in each daily routine class. Some of them also organize activities to show filial piety to their 
parents and express their filial piety.

\section{Summary}

Nowadays, the activities of the school and the training institutions outside school can be described as diverse. The meaning of filial piety is the mainstream value of traditional culture. It has become the main aspect of sinology education with both traditional and modern reasons. The concept of filial piety in Chinese education allows children to inherit outstanding traditional virtues and sympathize with their parents. In short, the holistic thought in contemporary Chinese primary and secondary education is mainly reflected in the traditional concept of filial piety.

\section{References}

[1] Feng Qi. Human Freedom and Truth, Goodness, and Beauty [M]. East China Normal University Press, 1997, page 120.

[2] Liu Xiaohong. On the Holism in the Traditional Chinese Value System and Its Transformation in Modern Times [J].Journal of Lanzhou University, 2000,(05):69-75.

[3] Chen Jianping. On Chinese Traditional Holism[J]. Journal of Direct Branch of Shanxi Provincial Party Committee School of Chinese Communist Party, 2004,(01):45-46.

[4] Li Ruilan and Ji Naili, New Theory of Self Cultivation, Family Harmony, Country Management and World Peace - Rational and Modern Values of Chinese Traditional Holistic Values[M]. Tianjin Academy of Social Sciences Press, 2001 edition.

[5] Yang Bojun. An Analysis of the Analects of Confucius[M]. Page 133, Zhonghua Book Company, 2009, p. 2

[6] Wang Wenjin, Translation and Explanation of The Book of Rites, $[\mathrm{M}]$, Zhonghua Book Company, 2016 edition.

[7] Yan Fang, He Xuexin. Progress and Problems in the Study of Sinology in Primary and Secondary Schools[J].Journal of Tianjin Academy of Education,2012(02):66-69.

[8] Zhang Xiaoguo, Tang Zhisong. The Chaos and Direction of Sinology Education in Primary and Secondary Schools[J].Modern Secondary and Primary Education,2012(04):1-3.

[9] Zhang Helong. Qian Mu Introduction to Sinology [D]. Central China Normal University, 2017.

[10] Hu Hongli. Exploration of the Intersection between Sinology Education and Modern Education [J].China Journal of Education, 2011(11):12-15.

[11][Yuan Xingyi: Contemporary Morphology and Significance of Sinology, Journal of Beijing University (Philosophy and Social Science Edition), No. 1, 2008, p. 70.

[12]Feng Qi. Human Freedom and Truth, Goodness, and Beauty [M]. East China Normal University Press, 1997, page 120.

[13] Liu Xiaohong. On the Holism in the Traditional Chinese Value System and Its Transformation in Modern Times [J].Journal of Lanzhou University, 2000,(05):69-75.

[14]Chen Jianping. On Chinese Traditional Holism[J]. Journal of Direct Branch of Shanxi Provincial Party Committee School of Chinese Communist Party, 2004,(01):45-46.

[15] Li Ruilan and Ji Naili, New Theory of Self Cultivation, Family Harmony, Country Management and World Peace - Rational and Modern Values of Chinese Traditional Holistic Values[M]. Tianjin Academy of Social Sciences Press, 2001 edition.

[16] Yang Bojun. An Analysis of the Analects of Confucius[M]. Page 133, Zhonghua Book Company, 2009, p. 2 